\title{
The Study of Corridor Height Influence on Fire Smoke Diffusion in Room-Corridor Fire
}

\author{
Zheli Xing ${ }^{1, a}$, Jinfeng Mao ${ }^{1, b}$, Chaofeng $\mathrm{Li}^{1, \mathrm{c}}$, Jin Zhou ${ }^{1, \mathrm{~d}}$, Pumin Hou ${ }^{1, \mathrm{e}}$
}

1 Institute of Military Environmental Teaching and Research, PLA University of Science and Technology, Nanjing 210007, China;

a zheli86@sina.com, ${ }^{\mathrm{b}}$ maojinfeng628@sina.com, ${ }^{\mathrm{c}}$ lichaofeng789@hotmail.com, dmingmeng.2006@163.com, ${ }^{\mathrm{e}}$ Igdxhpm@163.com

Keywords: corridor width; fire; smoke; room-corridor

Abstract. For researching the influence of the width of corridor to the smoke distribution in room-corridor geometry fire, based on similar principle to build a model-entity ratio of 1:4 model experiment system, conducted three conditions of model experiment, analyzed the temperature distribution in corridor, investigated the concentrations of $\mathrm{CO}, \mathrm{CO}_{2}, \mathrm{O}_{2}$ in corridor under different corridor width. The results showed that, the temperature in corridor decreased as corridor width increased; the concentrations of $\mathrm{CO}, \mathrm{CO}_{2}$ increased obviously and the concentrations of $\mathrm{O}_{2}$ descended with the decline of corridor width; the decline of corridor width would cause disadvantageous effect on the evacuation of occupants.

\section{Introduction}

Fire smoke is a mixture of combustion and pyrolysis products, it is one of the basic characteristic parameter of fire. After the fire, there will form a large number of high temperature smoke gas, and smoke is the main reason of casualties ${ }^{[1,2]}$. The high temperature of flue gas will not only pose a threat to personnel safety, also poses a great damage to equipment, engineering structures ${ }^{[3,4]}$.

Due to the devastating character of fire, model experiment becomes an important mean of fire research $^{[5]}$. The university of Virginia had set up a model for the structure of "room - corridor" test bench, study the smoke migration regularity under limited ventilation conditions ${ }^{[6]}$. Inspired by them, domestic fire researchers also establish and improve the small scale model test bench and has carried on the related research ${ }^{[7]}$.

In this paper, according to the principle of similar structures, " room - corridor" model experiment and data acquisition system is established. By varying working condition, the corridor height influence on the smoke diffusion regularity is studied, this paper can provide reference for building fire escape and fire rescue work.

\section{Experiment}

Test bench. Test bench's prototype is a protective engineering fire zone. The prototype consists of a fire room and a channel. The corridor size is $60 \mathrm{~m} \mathrm{x} 2 \mathrm{~m} \mathrm{x} 3 \mathrm{~m}$, the size of fire room is $4.8 \mathrm{~m} \times 3 \mathrm{~m}$ $\mathrm{x} 2.4 \mathrm{~m}$, and the open door of the room is $2 \mathrm{~m}$ high, $0.8 \mathrm{~m}$ wide, no Windows in the room, the end face of corridor near room is sealed and the end face far from the room is kept open.

In this paper, according to the similarity theory of heat conduction and key similarity criterion ${ }^{[5]}$, a 1:4 geometric proportion model is established. Model test bench size is shown in Fig. 1. The test bench is shown in Fig. 2.

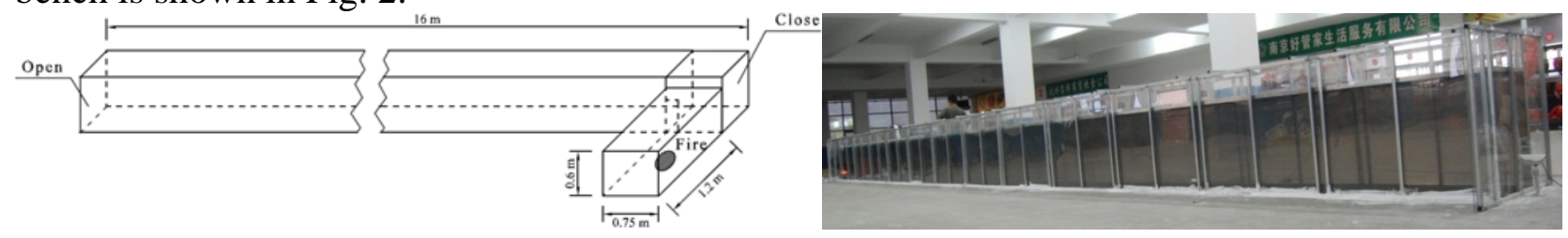

Fig. 1. Size of experiment model

Fig. 2. Demonstration of experiment model 
Fire Source. Model experiment fire source is a mixture of n-heptane and diesel, the hybrid volume ratio is 9:1. The circular oil pool's diameter is $10.1 \mathrm{~cm}$, the fuel is $100 \mathrm{ml}$.

Data Acquisition System. Thermocouple detect tree is made with the diameter of $0.5 \mathrm{~mm} \mathrm{~K}$ type thermocouple. The thermocouple measurement range is $0 \sim 1300{ }^{\circ} \mathrm{C}$, measuring accuracy is $0.4 \%$, the response time is $10 \mathrm{~s}$. The temperature data is displayed collection software after the process of temperature acquisition module R-8018BL and RS-485 communication bus.

The carbon monoxide, carbon dioxide and oxygen concentrations are measured at the same time by TESTO 310 smoke analyzer. Oxygen measurement accuracy is $0.2 \%$, the response time is $30 \mathrm{~s}$, the response time of $\mathrm{CO}$ and $\mathrm{CO}_{2}$ are $60 \mathrm{~s}$, the measuring accuracy of $\mathrm{CO}$ is $20 \mathrm{PPM}(0-400 \mathrm{ppm})$, 5\% (401-2000ppm), 10\% (2001-4000 ppm).

Test Conditions. The experiments are conducted in three conditions, the width of corridor are $0.4 \mathrm{~m}$ (case 1), $0.5 \mathrm{~m}$ (case 2), $0.6 \mathrm{~m}$ (case 3), respectively.

Arrangement of Measuring Points. In order to comprehensive record the temperature distribution in the model experiment, The "room-corridor" structure adopted eight group of thermocouple tree data acquisition system, as shown in Fig. 3.

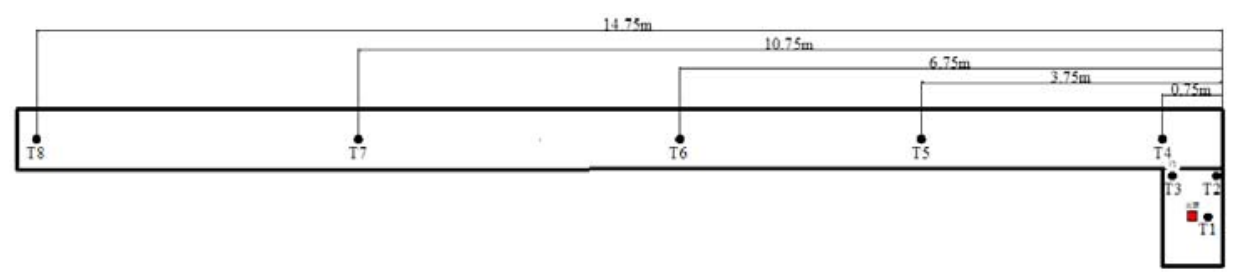

Fig. 3. Plane distribution of thermocouple tree

There are five thermocouple trees (T4-T8) in the corridor, each thermocouple tree contains six thermocouples, from the bottom to top are 1\#-6\#. The top and the bottom thermocouple respectively at distance with the ceiling and floor are $2 \mathrm{~cm}$ and $3 \mathrm{~cm}$, thermocouple distance are $14 \mathrm{~cm}$. In the coordinate from the fire $5 \mathrm{~m}$ (S1) and $10 \mathrm{~m}$ (S2) each have a smoke analyzer, The height of gas analyzer probe is $0.5 \mathrm{~m}$.

\section{Results and discussion}

Different Height Influence on the Temperature Distribution in the Corridor. Fig. 4 and 5 show the temperature in corridor with the changing of corridor width, as is shown in Fig. 4. With the increase of the width of the corridor, the highest temperature at the T5 decreases gradually, the temperature of $5 \#$ thermocouple also decrease with the width of the corridor increases. The 1\#, 2\#, $3 \#$ and $4 \#$ thermocouples change little, because they effected by hot smoke little. In Fig.5, it could be found that the temperature of $6 \#$ thermocouple have little difference in all the cases. At cases 1 and 2, the temperature of $5 \#$ and $6 \#$ are nearly same, at case 3 , because of the increase of corridor width, the entrainment between the hot smoke and air is strengthened, the $5 \#$ thermocouple temperature is slightly lower than 6\#, at the same time, think about the smoke sedimentation, the gas in lower part is effected by hot smoke more obviously in the distal of corridor. Therefore, the increase of corridor width has strengthened the entrainment between the hot smoke and the air, and intensified the heat transfer between them. So, just think in terms of temperature, in the hallway at constant height, increased corridor width is help to escape for people. 


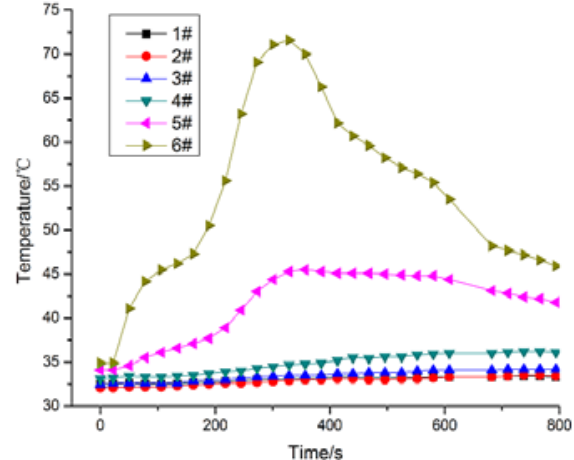

(a)case 1

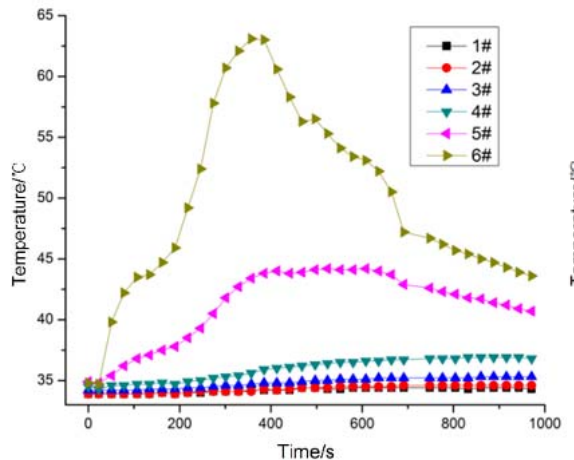

(b)case 2

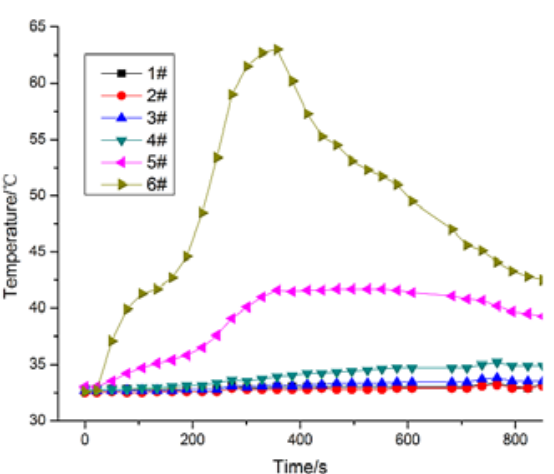

(c)case 3

Fig. 4. The distribution of temperature at $\mathrm{T} 5$ with different corridor width

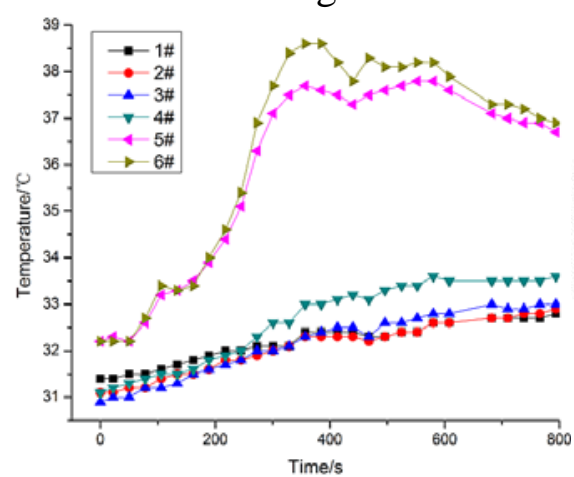

(a)case 1

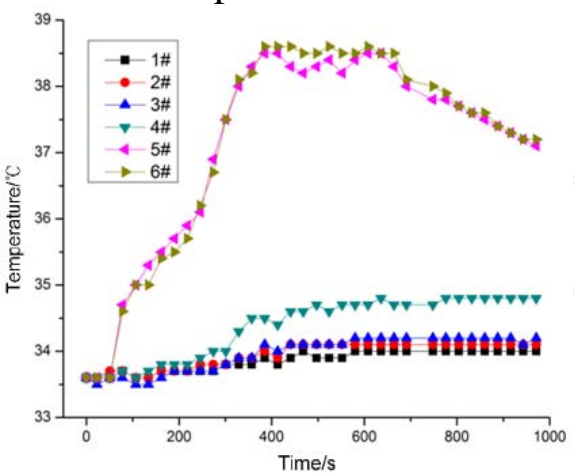

(b)case 2

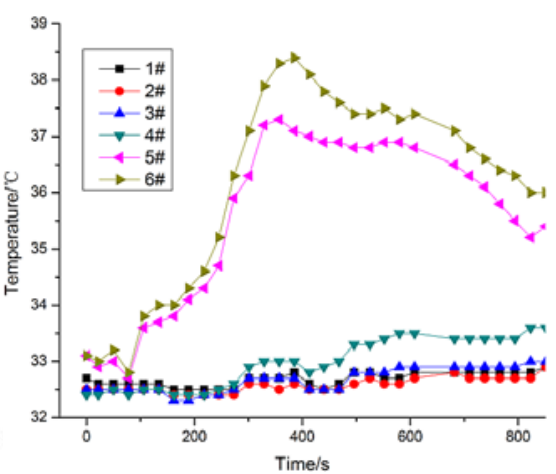

(c)case 3

Fig. 5. The distribution of temperature at $\mathrm{T} 7$ with different corridor width

Width Impacts on Carbon Monoxide Concentration in the Corridor. The Fig. 6 and Fig. 7 show that with the increase of corridor width measuring point in S1 and S2 maximum of CO concentration is reduced, at the same time, the increase rate of CO concentration decreases, the time reaching a $\mathrm{CO}$ density increased as the width of the corridor, therefore, with the increase of corridor width, flue gas diffusion rate decreases.

Comparing Figure 6 and Fig. 7, the first peak of the concentration of carbon monoxide in the S2 time than S1 of the first peak appeared late, the gradual spread of flue gas from the near to the distant, but because of the flue gas in the diffusion process temperature decreases and settlement, so S2 first peak higher than the first peak of S1, and with the increase of the width of the corridor, difference of S1 and S2 peak is greater. Although the CO peak concentration of the S1 and the rate of change reduced with the increase of corridor width, the peak of $\mathrm{CO}$ concentration and the change rate at the S2 decreased to a lesser extent, therefore corridor width increase is useful for escape, but at the distal of the fire, the increase of corridor width produce beneficial effects is not obvious. The escaping people should avoid thermal smoke damage near roof, and in the far end of the corridor, pay more attention to the flue gas of settlement and toxicity.

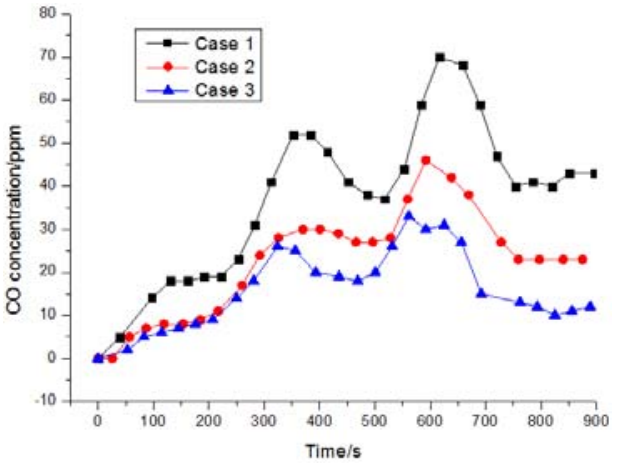

Fig. 6. The CO concentration at S1

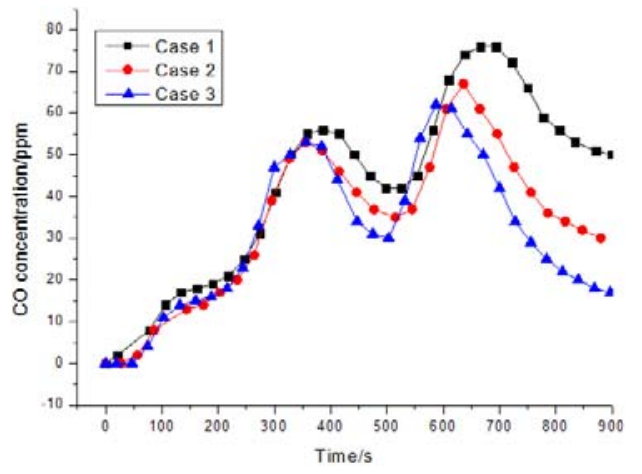

Fig. 7. The CO concentration at S2 
Analysis of Corridor Width Influence on Oxygen Concentration. The Fig. 8 and 9 show oxygen concentration in smoke changing with corridor width, the increase of cold air volume in the lower part of the corridor, which makes the phenomenon of entrainment more obvious, the minimum concentration of oxygen at S1 increases with the increase of corridor width. The minimum concentration of oxygen change slightly about $18.5 \%$ at S2 with different corridor. The minimum concentration have little difference between $\mathrm{S} 1$ and $\mathrm{S} 2$ at case 1 , the minimum concentration of oxygen at S2 is lower than S1 when case 2 and case 3, the difference was more obviously with the increase of corridor width. At the same time, the increase of corridor width is beneficial for smoke emission and air supply. From the perspective of oxygen, increase corridor width is beneficial for people escape.

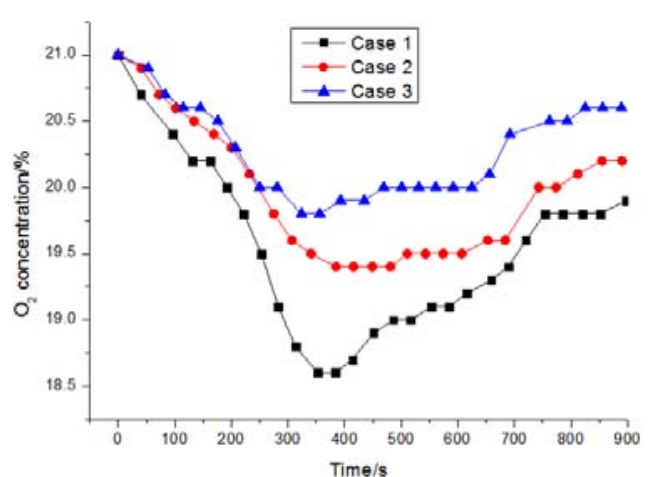

Fig. 8. The $\mathrm{O} 2$ concentration at $\mathrm{S} 1$

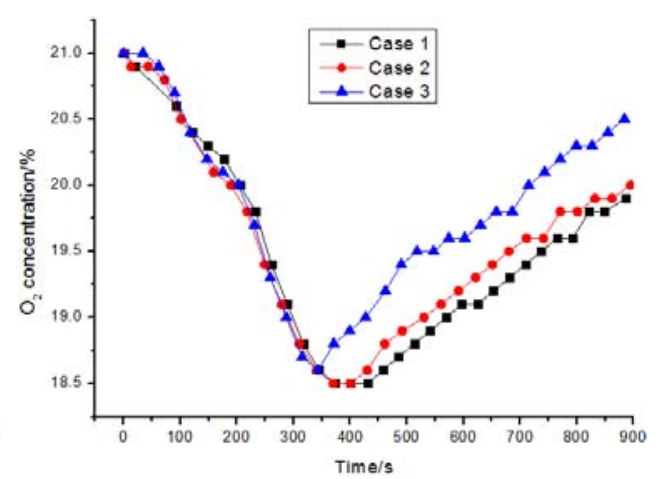

Fig. 9 The $\mathrm{O} 2$ concentration at S2

Analysis of Carbon Dioxide Concentration of Different Corridor Width. From Fig. 10 and 11 , the $\mathrm{CO}_{2}$ maximum concentration in the corridor decreases with the increase of the corridor width, and the reduce scape at $\mathrm{S} 1$ is larger than $\mathrm{S} 2$. The $\mathrm{CO}_{2}$ concentration at $\mathrm{S} 2$ is higher than $\mathrm{S} 1$, which is same to the above CO features.

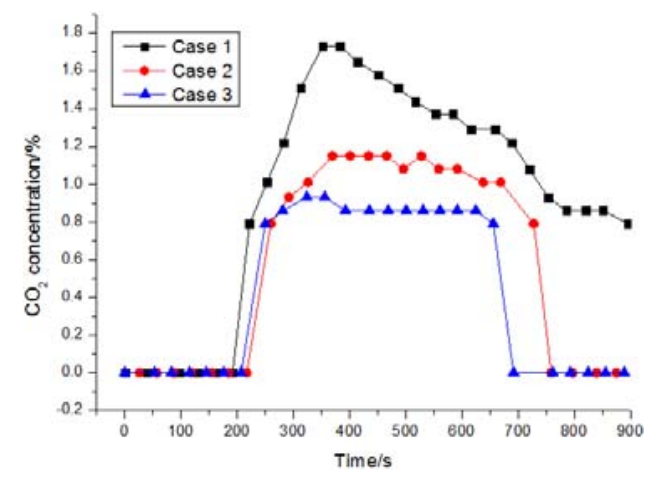

Fig. 10 The $\mathrm{CO}_{2}$ concentration at $\mathrm{S} 1$

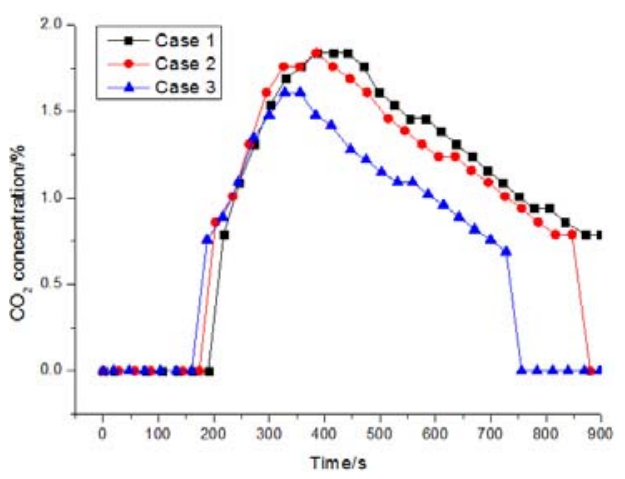

Fig. 11 The $\mathrm{CO}_{2}$ concentration at $\mathrm{S} 2$

\section{Conclusion}

In the case of constant height, considering the temperature, the concentration of $\mathrm{CO}, \mathrm{O}_{2}$ and $\mathrm{CO}_{2}$ comprehensively, increasing the corridor width is helpful for evacuation, the effect is obviously at the area near fire room. Because of the smoke sedimentation, the advantage would reduce in the distal of corridor. At the process of protective engineering design and construction, should increase the corridor width when objective condition permits. When fire happens in protective engineering, although people escape to the distal of corridor, people should also bow down and notice the sedimentation of smoke.

\section{References}

[1] Rui Huang, Lizhong Yang, Weifeng Fang, et al: China Engineering Science, 2002, 4(7):80-85. 
[2] Lizhong Yang, Weifeng Fang: Fire Safety Science, 2001, 10(1):29-33.

[3] Zhongyou Li, Yuanxue Liu, Shulin Liu, et al: Rock and Soil Mechanics. 2012, 33(2):307-310.

[4] Zhi Lin, Jun Guo, Qiang Li: Technology of Highway and Transport. 2012(6):92-96.

[5] Yijun Yao. Model Experiment of Smoke Controlling in Natural Ventilation Mode for City Tunnels[D]. Nanjing: PLA Univ. of Sci. \& Tech., 2008.

[6] Lattimer, B. Y., Vandsburger, U.， Roby, R. J:Fire Technology， 1998(34):325-355.

[7] Tingyong Fang, Lizhong Yang, Wenxing Feng, et al: Journal of Combustion Science and Technology. 2005, 11(1):62-67. 